Research Article

\title{
Characteristics and Applications of Sewage Sludge Biochar Modified by Ferrous Sulfate for Remediating Cr(VI)-Contaminated Soils
}

\author{
Yuan-Yuan Li $\mathbb{D},{ }^{1}$ Ting-Ting Zhang $\mathbb{D},{ }^{2}$ Zhi Ning, ${ }^{2}$ and Jin-Hong Chen ${ }^{3}$ \\ ${ }^{1}$ Qingdao University of Technology, Qingdao 266033, China \\ ${ }^{2}$ Wisdri City Environment Protection Engineering Limited Company, Wuhan 430205, China \\ ${ }^{3}$ Wuchang Shouyi University, School of Urban Construction, Wuhan 430070, China \\ Correspondence should be addressed to Yuan-Yuan Li; yyliqd@outlook.com and Ting-Ting Zhang; ttz_dshb@163.com
}

Received 8 January 2020; Revised 14 August 2020; Accepted 3 September 2020; Published 29 September 2020

Academic Editor: Kirk Hatfield

Copyright $(2020$ Yuan-Yuan Li et al. This is an open access article distributed under the Creative Commons Attribution License, which permits unrestricted use, distribution, and reproduction in any medium, provided the original work is properly cited.

Background. Soil contamination by hexavalent chromium is becoming a main environmental concern in China. This study developed a sewage sludge biochar modified by $\mathrm{FeSO}_{4}(\mathrm{CHBC})$ as a new reductant for $\mathrm{Cr}(\mathrm{VI})$-contaminated soil. The effectiveness of CHBC-stabilized $\mathrm{Cr}(\mathrm{VI})$-contaminated soil was investigated. Methods. Typical industrial $\mathrm{Cr}(\mathrm{VI})$-contaminated soil in China was chosen as the medium. The total and $\mathrm{Cr}(\mathrm{VI})$ contents of the contaminated soil were $1014.6 \mathrm{and} 973.5 \mathrm{mg} / \mathrm{kg}$, respectively. The effectiveness of the $\mathrm{Cr}(\mathrm{VI})$-contaminated soil stabilized by $\mathrm{CHBC}$ was investigated by the leaching test (US EPA method 1312), the simplified bioaccessibility extraction test (US EPA 2007 protocol and British Geological Survey), alkaline digestion (US EPA method 3060A), sequential extraction (BCR sequential extraction procedure), X-ray diffraction, and the risk assessment code test. Results. Results show that CHBC substantially reduced the leachability and $\mathrm{Cr}(\mathrm{VI})$ content of the contaminated soil. The leachability and content of $\mathrm{Cr}(\mathrm{VI})$ were lower than the thresholds of the Environmental Quality Standards of Soil in China for civil reuse and the China Environmental Quality Standards of surface water for civil use when the soil was stabilized with $10 \%$ dosage of CHBC. Conclusion. $\mathrm{CHBC}$ is highly efficient in stabilizing $\mathrm{Cr}(\mathrm{VI})$ and can effectively reduce the leachability and bioavailability of $\mathrm{Cr}$ in contaminated soil and thus feasible for stabilizing $\mathrm{Cr}(\mathrm{VI})$-contaminated soil and shows potential for application in the field.

\section{Introduction}

Chromium (Cr) is a common soil contaminant, and nearly $1.1 \%$ of China's land is contaminated by $\mathrm{Cr}$ according to Chinese officials $[1-3]$. Cr often exists in soil in two main redox states: $\mathrm{Cr}(\mathrm{III})$ and $\mathrm{Cr}(\mathrm{VI})$. $\mathrm{Cr}(\mathrm{III})$ is a nutrient for plant growth, while $\mathrm{Cr}(\mathrm{VI})$ is highly toxic and has been added to Class A human carcinogens [4]. Given its carcinogenic and toxic properties, efforts have been exerted in removing $\mathrm{Cr}(\mathrm{VI})$ from contaminated soil. Chemical reduction has been widely used for removing $\mathrm{Cr}(\mathrm{VI})$ from soil due to its speed and effectiveness [5]. Ferric salts (nano-zero valent iron, bivalent iron, and ferrous sulfate) and sulfides (calcium polysulfide and sodium thiosulfate) are promising reagents that have been used in large amounts of Cr-contaminated soil for many years. However, ferric salts and sulfides have adverse effects due to the acidity or high-sulfur content they impart to the soil $[6,7]$. Thus, green, environmentally friendly reducing agents must be urgently developed as substitutes for ferric salts and sulfides. The use of biochar as a reducing agent to remove $\mathrm{Cr}(\mathrm{VI})$ has been extensively investigated [8-15]. Dong et al. [8] successfully applied the biochar from sugar beet tailings to reduce $\mathrm{Cr}(\mathrm{VI})$ in aqueous solutions and obtained favorable results. Agrafioti et al. [9] used the biochar from sewage sludge treated with $\mathrm{Cr}(\mathrm{VI})$-contaminated water and observed its high capacity to adsorb $\mathrm{Cr}(\mathrm{VI})(64.1 \mathrm{mg} / \mathrm{g})$. Ma et al. [10] discovered that biochar is a useful adsorbent for removing $\mathrm{Cr}(\mathrm{VI})$ from aqueous solutions. Shen et al. [11] reported that the biochar from coconut coir has a high capacity to reduce $\mathrm{Cr}(\mathrm{VI})(124 \mathrm{mg} / \mathrm{g})$. Zhou et al. [12] used biochar and acidified manure treated with $\mathrm{Cr}(\mathrm{VI})$-contaminated soil and 
observed their high capacity to adsorb $\mathrm{Cr}(\mathrm{VI})(34.1 \mathrm{mg} / \mathrm{g})$. Xia et al. [13] found that biochar is a promising material for remediated $\mathrm{Cr}(\mathrm{VI})$-contaminated soils and wastewater, displaying factors that affect the removal efficiency of $\mathrm{Cr}(\mathrm{VI})$, including $\mathrm{pH}$, temperature, initial concentration, reaction time, biochar characteristics, and coexisting contaminants. Li et al. [14] compared the biochars from maize stalk and peanut shell for reduced $\mathrm{Cr}(\mathrm{VI})$ in soils. Their results show that the maximum $\mathrm{Cr}(\mathrm{VI})$ reduction capacities of maize stalk and peanut shell were 238 and $231 \mathrm{mg} / \mathrm{kg}$, respectively. Pei et al. [15] applied the biochar from vinegarresidue-supported nanoscale zero-valent iron to remediate $\mathrm{Cr}(\mathrm{VI})$ contaminated soil and found that it could achieve $\mathrm{Cr}(\mathrm{VI})$ and $\mathrm{Cr}$ immobilization efficiencies of $100 \%$ and $91.83 \%$ at $10 \%$ dosage, respectively.

According to previous studies, the biochars derived from sewage sludge, sugar beet tailings, and rice husk have great potential for remediating $\mathrm{Cr}(\mathrm{VI})$ contamination. However, considerably high reduction capacities must be achieved to accelerate the application of biochars in $\mathrm{Cr}(\mathrm{VI})$-contaminated water and soil. Modification by using iron salts is a promising method of improving the reduction capacities. Zero valent iron modification offers effective absorptivity and reducing capacity $[16,17]$. However, zero valent iron is characterized by high costs, difficult production, and difficult storage. Ferrous sulfate $\left(\mathrm{FeSO}_{4}\right)$, which is relatively inexpensive and highly effective for remediating $\mathrm{Cr}(\mathrm{VI})$-contaminated soil, can substitute for zero valent iron. China is the largest producer of sewage sludge, generating more than 80 million metric tons every year [18]. A small proportion of sewage sludge is used in the agriculture sector and burned, while the rest ends up in landfills or is discarded, causing environmental problems [19]. A prior work showed that the biochar from sewage sludge has effective absorptivity, high reducing capacity, and various chemical functional groups [20]. The modified biochar derived from sewage sludge has great potential for $\mathrm{Cr}(\mathrm{VI})$-contaminated soil remediation. However, no peer-reviewed literature has methodically investigated the stability of the sewage sludge biochar modified by $\mathrm{FeSO}_{4}$ in $\mathrm{Cr}(\mathrm{VI})$-contaminated soil.

This study developed a sewage sludge biochar modified by $\mathrm{FeSO}_{4}(\mathrm{CHBC})$ as a new reductant for $\mathrm{Cr}(\mathrm{VI})$-contaminated soil. The effectiveness of the $\mathrm{CHBC}$-stabilized $\mathrm{Cr}(\mathrm{VI})$-contaminated soil was investigated by the leaching test (SPLP), the simplified bioaccessibility extraction test (SBET), alkaline digestion, sequential extraction, X-ray diffraction (XRD), and the risk assessment code (RAC). This study can provide a new reductant for stabilized $\mathrm{Cr}(\mathrm{VI})$-contaminated soil and is relatively valuable for sewage sludge resource reuse.

\section{Materials and Methods}

2.1. Cr(VI)-Contaminated Soil. Cr(VI)-contaminated soil was collected from a Cr-contaminated site in the Qingdao Red Star Chemical Group, Qingdao City, Shandong Province, China (Figure 1). The $\mathrm{Cr}(\mathrm{VI})$-contaminated soil was sieved (2-mm mesh) and homogenized to obtain a composite sample. Table 1 presents the physicochemical properties of the soil.
2.2. Sewage Sludge Biochar Modified by Ferrous Sulfate. The sewage sludge collected from the Qingdao Tuandao cape wastewater treatment plant was air dried and then sieved through a $0.15 \mathrm{~mm}$ mesh. We manufactured a sewage sludge biochar by modifying the approach of Su et al. [21]. Briefly, the pretreated sewage sludge was pyrolyzed in an oxygen-free furnace at $400^{\circ} \mathrm{C}$ for $2 \mathrm{~h}$. After cooling, the biochar particles were ground and then sieved through a $0.075 \mathrm{~mm}$ screen. The sewage sludge biochar was then soaked in $\mathrm{FeSO}_{4}$ solution of $2 \mathrm{M}$ for $1 \mathrm{~h}$ in an oxygen-free condition. Then, the solids were finally vacuum-dried at $60{ }^{\circ} \mathrm{C}$. This sewage-sludge-biochar-supported $\mathrm{FeSO}_{4}$ was identified as "CHBC." The sewage sludge and CHBC are presented in Figure 2. The physicochemical properties of the sewage sludge and CHBC are presented in Table 2.

2.3. Sample Preparation. CHBC was added to the $\mathrm{Cr}(\mathrm{VI})$ contaminated soil at reductant-to-dry soil ratios of $0 \%, 1 \%$, $3 \%, 5 \%$, and $10 \%$. The experimental design for the stability study is presented in Table 3. CHBC- and $\mathrm{Cr}(\mathrm{VI})$-contaminated soils were mixed using a Spar mixer. Deionized water was then added to the mixture until the water content reached $30 \%$. The mixture was withdrawn from sealed plastic bottles after 28 days of incubation at room temperature to allow the $\mathrm{CHBC}$ - and $\mathrm{Cr}(\mathrm{VI})$-contaminated soils to react adequately. Figure 3 presents the $\mathrm{CHBC}$-stabilized $\mathrm{Cr}(\mathrm{VI})$-contaminated soil.

2.4. Chemicals. The $\mathrm{FeSO}_{4}$ heptahydrate $\left(\mathrm{FeSO}_{4} \cdot 7 \mathrm{H}_{2} \mathrm{O}\right)$, concentrated sulfuric acid $\left(\mathrm{H}_{2} \mathrm{SO}_{4}\right)$, nitric acid $\left(\mathrm{HNO}_{3}\right)$, hydrochloric acid $(\mathrm{HCl})$, sodium carbonate $\left(\mathrm{Na}_{2} \mathrm{CO}_{3}\right)$, sodium hydroxide $(\mathrm{NaOH})$, magnesium chloride $\left(\mathrm{MgCl}_{2}\right)$, diphenylcarbazide $\left(\mathrm{C}_{13} \mathrm{H}_{14} \mathrm{~N}_{4} \mathrm{O}\right)$, acetic acid $\left(\mathrm{CH}_{3} \mathrm{COOH}\right)$, hydrochloric acid amide $\left(\mathrm{NH}_{2} \mathrm{OH} . \mathrm{HCl}\right)$, hydrogen peroxide $\left(\mathrm{H}_{2} \mathrm{O}_{2}\right)$, ammonium acetate $\left(\mathrm{CH}_{3} \mathrm{COONH}_{4}\right)$, hydrofluoric acid (HF), and perchloric acid $\left(\mathrm{HClO}_{4}\right)$ used as ACS-certified reagents in this study were purchased from Sinopharm Chemical Reagent Co Ltd., China.

\section{Test Methods}

The heavy metal contents of the contaminated soil, sewage sludge, and magnetic biochar were determined by EPA Method 3050B (soil acid digestion) [22]. Briefly, $1 \mathrm{~g}$ of representative soil was dried at $110^{\circ} \mathrm{C}$ and placed in a glass test tube with a reflux system. After adding $10 \mathrm{~mL}$ of concentrated $\mathrm{HCl}$, the sample was heated to $95^{\circ} \mathrm{C}$ and kept in agitation for $15 \mathrm{~min}$. The glass test tube was cooled to $25^{\circ} \mathrm{C}$, and $15 \mathrm{~mL}$ of $\mathrm{HNO}_{3}$ was then added to the solution. The mixture's temperature was then maintained at $95^{\circ} \mathrm{C}$ for $2 \mathrm{~h}$ and subsequently cooled down to $25^{\circ} \mathrm{C}$. After the addition of $2 \mathrm{~mL}$ of $\mathrm{H}_{2} \mathrm{O}$ and $10 \mathrm{~mL}$ of $\mathrm{H}_{2} \mathrm{O}_{2}$, the solution was heated to $95^{\circ} \mathrm{C}$ for $2 \mathrm{~h}$. The leachate was filtrated through a polycarbonate filter with an effective pore size of $0.45 \mu \mathrm{m}$. The $\mathrm{Cr}$ and $\mathrm{Cr}(\mathrm{VI})$ concentrations in the filtrate were measured using inductively coupled plasma mass spectrometry (ICPMS) and colorimetric analyses, respectively. 


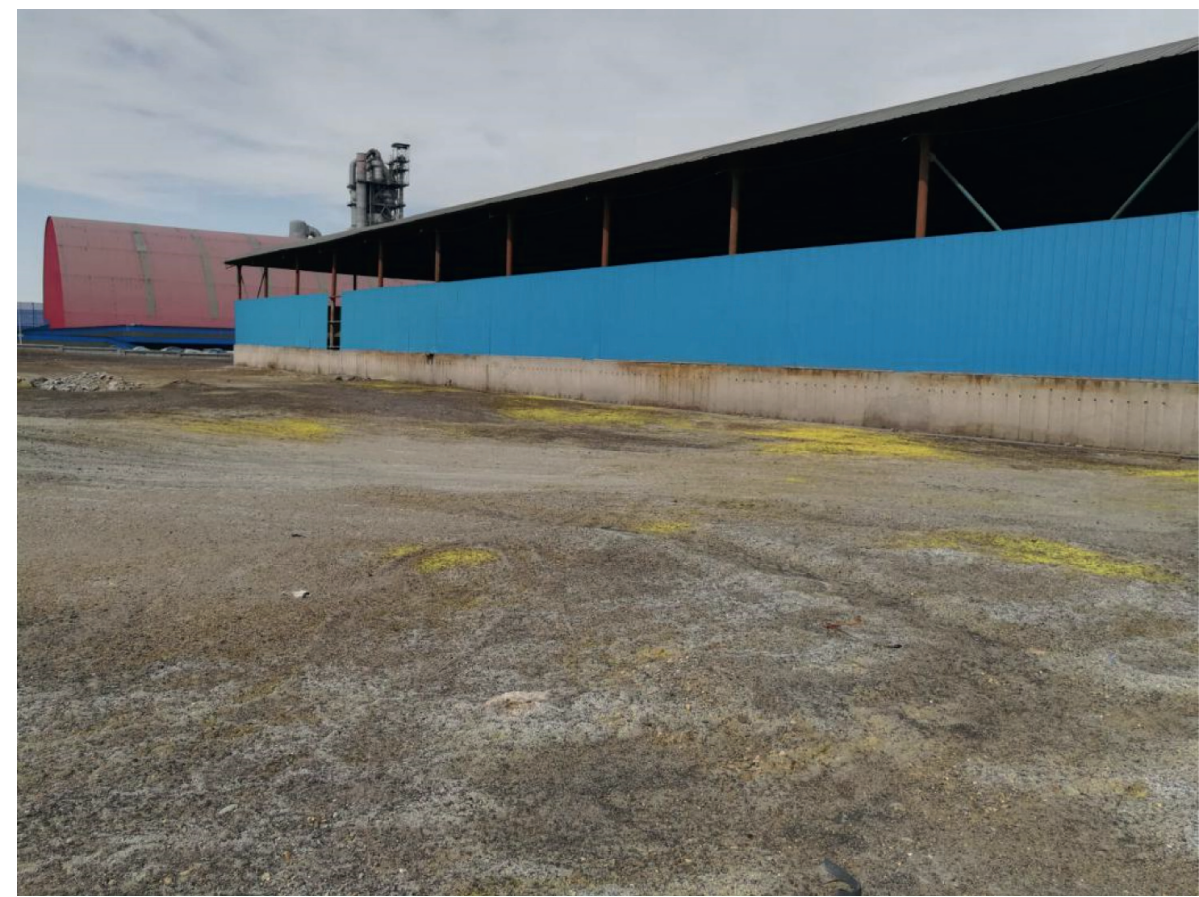

FIGURE 1: Picture of chromium contaminated site.

TABle 1: Physicochemical properties of $\mathrm{Cr}(\mathrm{VI})$ contaminated soil.

\begin{tabular}{lccccc}
\hline Index & Water content (\%) & Organic content (\%) & pH & Total Cr & Cr(VI) \\
\hline Value & 27.26 & 1.75 & 9.80 & $1014.6 \mathrm{mg} / \mathrm{kg}$ & $973.5 \mathrm{mg} / \mathrm{kg}$ \\
\hline
\end{tabular}

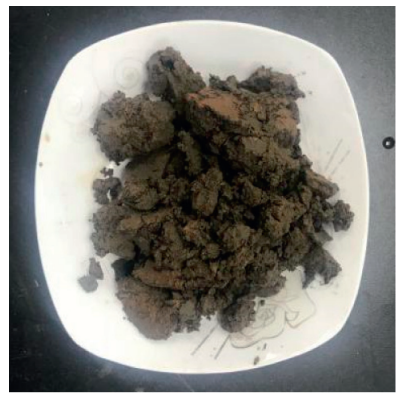

(a)

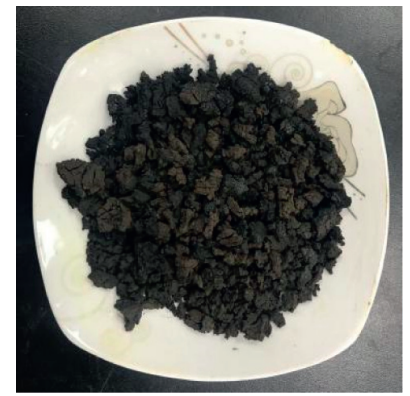

(b)

Figure 2: Picture of sewage sludge and CHBC. (a) Sewage sludge. (b) CHBC.

The leachability of $\mathrm{Cr}(\mathrm{VI})$ and $\mathrm{Cr}$ was determined by a synthetic precipitation leaching procedure (i.e., US EPA method 1312) [23]. Briefly, $10 \mathrm{~g}$ of the sample was mixed with $200 \mathrm{~mL}$ of SPLP extraction fluid and tumbled for $18 \mathrm{~h}$ at $30 \pm 2 \mathrm{rpm}$. The leachate was filtrated through a polycarbonate filter with an effective pore size of $0.45 \mu \mathrm{m}$. The $\mathrm{Cr}$ concentration in the filtrate was measured using ICP-MS.

The $\mathrm{Cr}(\mathrm{VI})$ content was determined by an alkaline digestion method (i.e., US EPA method 3060A) [24]. The $\mathrm{Cr}$ (VI) concentration in the leachate was measured by colorimetric analysis (i.e., the US EPA method 7196A) [25]. Briefly, $5 \mathrm{~g}$ of representative soil was digested in a phosphate- buffered alkaline digestion solution $\left(0.28 \mathrm{M} \mathrm{Na}_{2} \mathrm{CO}_{3} / 0.5 \mathrm{M}\right.$ $\mathrm{NaOH}$ ) at $90^{\circ} \mathrm{C}-95^{\circ} \mathrm{C}$ for approximately $60-65 \mathrm{~min}$. Then, $100 \mathrm{mg}$ of $\mathrm{Mg}^{2+}$ in the form of magnesium chloride was also added to the digestion solution to suppress the oxidation of $\mathrm{Cr}$ (III). The digested solution was cooled to room temperature. The leachate was filtrated through a polycarbonate filter with an effective pore size of $0.45 \mu \mathrm{m}$. The concentration of $\mathrm{Cr}(\mathrm{VI})$ in the filtrate was measured using colorimetric analysis.

The bioaccessibility of $\mathrm{Cr}(\mathrm{VI})$ and $\mathrm{Cr}$ was determined by the US EPA protocol [26] and the British Geological Survey [27]. Briefly, $5 \mathrm{~g}$ of sample was mixed with $500 \mathrm{~mL}$ 
TABle 2: Physicochemical properties of sewage sludge and CHBC.

\begin{tabular}{lcc}
\hline Items & Sewage sludge & CHBC \\
\hline Water content $(\%)$ & 78.65 & - \\
Organic content $(\%)$ & 81.34 & - \\
$\mathrm{pH}$ & 6.31 & 7.96 \\
Total N (\%) & 2.72 & 1.14 \\
Total P (\%) & 1.81 & 2.18 \\
$\mathrm{BET}$ specific surface area $\left(\mathrm{m}^{2} / \mathrm{g}\right)$ & - & 24.73 \\
$\mathrm{Cu}(\mathrm{mg} / \mathrm{kg})$ & 75.63 & 75.12 \\
$\mathrm{Zn}(\mathrm{mg} / \mathrm{kg})$ & 56.27 & 54.32 \\
$\mathrm{~Pb}(\mathrm{mg} / \mathrm{kg})$ & 81.32 & 78.71 \\
$\mathrm{Cr}(\mathrm{mg} / \mathrm{kg})$ & 67.85 & 68.46 \\
$\mathrm{Ni}(\mathrm{mg} / \mathrm{kg})$ & 73.64 & 72.17 \\
$\mathrm{Cd}(\mathrm{mg} / \mathrm{kg})$ & 2.32 & 2.56 \\
$\mathrm{Hg}(\mathrm{mg} / \mathrm{kg})$ & 0.12 & 0.11 \\
$\mathrm{As}(\mathrm{mg} / \mathrm{kg})$ & 0.78 & 0.64 \\
\hline
\end{tabular}

TABle 3: Experimental design for the stability study.

\begin{tabular}{lccc}
\hline Test no. & Cr(VI)-contaminated soil $(\mathrm{kg})$ & CHBC dosage $(\mathrm{kg})$ & CHBC dosage $(\%)$ \\
\hline 1 & 5 & 0 & 0 \\
2 & 5 & 0.05 & 1 \\
3 & 5 & 0.15 & 3 \\
4 & 5 & 0.25 & 5 \\
5 & 5 & 0.5 & 10 \\
\hline
\end{tabular}

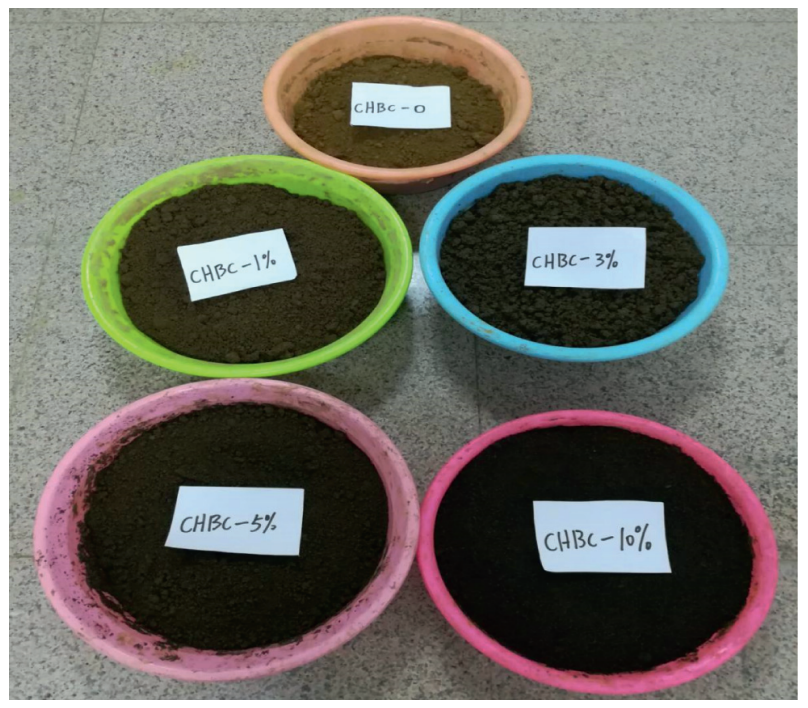

Figure 3: Picture of Cr(VI)-contaminated soil stabilized by CHBC.

of SBET extraction fluid and tumbled for $2 \mathrm{~h}$ at $30 \pm 2 \mathrm{rpm}$ at $37^{\circ} \mathrm{C}$. The leachate was filtrated through a polycarbonate filter with an effective pore size of $0.45 \mu \mathrm{m}$. The $\mathrm{Cr}$ and $\mathrm{Cr}(\mathrm{VI})$ concentrations in the filtrate were measured using ICP-MS and colorimetric analysis, respectively.

The species distribution of $\mathrm{Cr}$ was measured by the BCR sequential extraction procedure [28]. The sequential extraction procedure consisted of four steps, namely, the exchangeable, reducible, oxidizable, and residue fractions. Briefly, $2 \mathrm{~g}$ of the sample was tested using the sequential extraction procedure. The exchangeable fraction was determined through the extraction with $80 \mathrm{~mL}$ of $0.11 \mathrm{M}$ $\mathrm{HOAc}$ for $16 \mathrm{~h}$ at $30 \pm 2 \mathrm{rpm}$ at room temperature. The reducible fraction was determined through the extraction with $80 \mathrm{~mL}$ of $0.5 \mathrm{M} \mathrm{NH} \mathrm{NH}_{2} \mathrm{OH}$.HCL and $0.05 \mathrm{M} \mathrm{HNO}_{3}$ for $16 \mathrm{~h}$ at $30 \pm 2 \mathrm{rpm}$ at room temperature. The oxidizable fraction was determined through the extraction with $20 \mathrm{~mL}$ of $8.8 \mathrm{M} \mathrm{H}_{2} \mathrm{O}_{2}$ and $100 \mathrm{~mL}$ of $1 \mathrm{M} \mathrm{NH}_{4} \mathrm{OAc}$ with a $\mathrm{pH}$ of 2.0 for $16 \mathrm{~h}$ at $30 \pm 2 \mathrm{rpm}$ at room temperature. The residual fraction was determined after digestion with $60 \mathrm{~mL}$ of mixed acid $\left(20 \mathrm{~mL}\right.$ of each of $\mathrm{HNO}_{3}, \mathrm{HClO}_{4}$, and $\mathrm{HF}$ ) for $3 \mathrm{~h}$.

The sequential extraction procedure is presented in Table 4 . The risk assessment of $\mathrm{Cr}$ was measured by the RAC [29]:

$$
\operatorname{RAC}(\%)=\left(\frac{\sum_{n=1}^{1} F_{n}}{\sum_{n=1}^{4} F_{n}}\right) \times 100,
$$

where $F_{n}$ is the concentration of $\mathrm{Cr}$ in the nth fraction. The RAC criteria are presented in Table 5.

A Youke $722 \mathrm{~N}$ spectrophotometer was used at the $540 \mathrm{~nm}$ optical path to determine the $\mathrm{Cr}(\mathrm{VI})$ concentrations in the leachate. Turbidity blanks were incorporated into the analysis procedure. The $\mathrm{Cr}(\mathrm{VI})$ solution was used in $\mathrm{K}_{2} \mathrm{CrO}_{4}$ form to calibrate the spectrophotometer. Blank and spike recoveries were conducted to check the accuracy of the method.

Agilent 7700 ICP-MS was used to determine the $\mathrm{Cr}$ concentrations in the leachate. For quality control purposes, the Cr ICP standard was used to calibrate the ICP-MS, and quality control blank and spikes were measured for every 10 samples per batch. 
TABLE 4: Sequential extraction procedure.

\begin{tabular}{|c|c|c|}
\hline Step & Extraction procedure & Chemical phases \\
\hline 1 & Extracted by $0.11 \mathrm{~mol} / \mathrm{L}$ of $\mathrm{HOAc}$ at a liquid to solid $(\mathrm{L} / \mathrm{S})$ ratio of 40 & $\begin{array}{l}\text { Exchangeable } \\
\text { fraction }\end{array}$ \\
\hline 2 & Extracted by $0.5 \mathrm{~mol} / \mathrm{L}$ of $\mathrm{NH}_{2} \mathrm{OH} \cdot \mathrm{HCl}$ (adjusted to $\mathrm{pH}=1.5$ with $\mathrm{HNO}_{3}$ ) at a liquid to solid $(\mathrm{L} / \mathrm{S}$ ) ratio of 40 & Reducible fraction \\
\hline 3 & $\begin{array}{l}\text { Extracted by } 8.8 \mathrm{~mol} / \mathrm{l} \text { of } \mathrm{H}_{2} \mathrm{O}_{2} \text { at a liquid to solid }(\mathrm{L} / \mathrm{S}) \text { ratio of } 10 \text {, and then extracted by } 1 \mathrm{~mol} / \mathrm{l} \text { of } \mathrm{NH}_{4} \mathrm{OAc} \\
\text { (adjusted to } \mathrm{pH}=2.0 \text { with } \mathrm{HNO}_{3} \text { ) at a liquid to solid }(\mathrm{L} / \mathrm{S}) \text { ratio of } 50\end{array}$ & Oxidizable fraction \\
\hline 4 & $\mathrm{HNO}_{3}$-HF-HClO 4 digestion & Residual fraction \\
\hline
\end{tabular}

TABLE 5: RAC criteria.

\begin{tabular}{lcc}
\hline Grade & Exchangeable fraction content & Risk \\
\hline I & $<1$ & No risk \\
II & $1-10$ & Low risk \\
III & $11-30$ & Medium risk \\
IV & $30-50$ & High risk \\
V & 50 & Very risk \\
\hline
\end{tabular}

\section{Results and Discussion}

4.1. Cr(VI) Content of Stabilized Soils. Cr(VI) content is a key parameter for ensuring the reuse environmental security of stabilized soil. The Ministry of Ecology and Environment of China recommends risk screening and intervention values of 3.0 and $30 \mathrm{mg} / \mathrm{kg}$, respectively, for the $\mathrm{Cr}(\mathrm{VI})$ content in first-category development lands. The risk screening and intervention values of secondcategory development lands are 5.7 and $78 \mathrm{mg} / \mathrm{kg}$, respectively. According to the "Soil Environment Quality Risk Control Standard for Soil Contamination of Development Land" (GB36600-2018) [30], residential, medical and health, and education lands belong to firstcategory development lands and industrial, transportation, and green belong to second-category development lands. Figure 4 shows that the $\mathrm{Cr}(\mathrm{VI})$ content changed substantially for all stabilized soils and decreased considerably at increased $\mathrm{CHBC}$ dosage. When the $\mathrm{CHBC}$ dosage increased from $0 \%$ to $10 \%$, the $\mathrm{Cr}(\mathrm{VI})$ content decreased from $970.1 \mathrm{mg} / \mathrm{kg}$ to $1.2 \mathrm{mg} / \mathrm{kg}$. Figure 4 shows that the $\mathrm{Cr}(\mathrm{VI})$ content in CHBC-stabilized soil with $3 \%$ dosage was below the risk screening value of second-category development lands $(5.7 \mathrm{mg} / \mathrm{kg})$ and the risk screening value of first-category development lands $(3.0 \mathrm{mg} / \mathrm{kg})$ was achieved with a CHBC dosage of $5 \%$ [30]. Zhang et al. studied the $\mathrm{Cr}(\mathrm{VI})$ content of a contaminated soil stabilized by $\mathrm{FeSO}_{4}$ and $\mathrm{CaS}_{5}$. The $\mathrm{Cr}(\mathrm{VI})$ content of the stabilized soil decreased from 168 to $94 \mathrm{mg} / \mathrm{kg}$ to 21 and $4.2 \mathrm{mg} / \mathrm{kg}$ when the reductant dosage increased from $1 \%$ to $5 \%$, respectively [31]. These results indicate that $\mathrm{CHBC}$ is more advantageous than $\mathrm{FeSO}_{4}$ and $\mathrm{CaS}_{5}$ in stabilized $\mathrm{Cr}(\mathrm{VI})$ soil. $\mathrm{CHBC}$ has a higher reduction capability than $\mathrm{FeSO}_{4}$ and $\mathrm{CaS}_{5}$ and could substantially reduce the $\mathrm{Cr}(\mathrm{VI})$ content of contaminated soil.
4.2. Leachability of $\mathrm{Cr}$ and $\mathrm{Cr}(\mathrm{VI})$ of Stabilized Soils. Figure 5 shows the leachability of the $\mathrm{Cr}$ and $\mathrm{Cr}(\mathrm{VI})$ of stabilized soils with different CHBC dosages. The $\mathrm{Cr}(\mathrm{VI})$ and $\mathrm{Cr}$ concentrations decreased with the increase in $\mathrm{CHBC}$ dosage. When the $\mathrm{CHBC}$ dosage increased from $0 \%$ to $10 \%$, $\mathrm{Cr}(\mathrm{VI})$ and the total $\mathrm{Cr}$ decreased from 38.6 and $40.1 \mathrm{mg} / \mathrm{L}$ to 0.024 and $0.07 \mathrm{mg} / \mathrm{L}$, respectively. Figure 5 shows that the $\mathrm{Cr}(\mathrm{VI})$ and $\mathrm{Cr}$ concentrations of stabilized soils satisfy the Standards for Hazardous Waste regulatory limits in China (5 and $15 \mathrm{mg} / \mathrm{L}$, respectively) at respective $\mathrm{CHBC}$ dosages of $1 \%$ and 3\%; the values were also within the Standard for Pollution Control on the landfill site of the municipal solid waste regulatory limit in China $(1.5 \mathrm{mg} / \mathrm{L}$ for $\mathrm{Cr}(\mathrm{VI})$ and $4.5 \mathrm{mg} / \mathrm{L}$ for $\mathrm{Cr}$ ) $[32,33]$. The $\mathrm{Cr}(\mathrm{VI})$ concentrations of stabilized soils were lower than the China Environmental Quality Standards of surface water for the agriculture and civil use regulatory limits $(0.1$ and $0.05 \mathrm{mg} / \mathrm{L})$ at respective $\mathrm{CHBC}$ dosages of $5 \%$ and $10 \%$ [34]. This phenomenon occurred because $\mathrm{Cr}(\mathrm{VI})$ was reduced to $\mathrm{Cr}$ (III) by $\mathrm{FeSO}_{4}$, whereas $\mathrm{Cr}$ (III) formed the $\mathrm{Cr}_{\mathrm{x}} \mathrm{Fe}_{1-\mathrm{x}}(\mathrm{OH})_{3}$ precipitate and complexations or complexed with functional groups [11]. Dong et al. [8] and Chen et al. [18] observed that many active functional groups $(\mathrm{C}-\mathrm{H}, \mathrm{C}=\mathrm{O}$, $\mathrm{C}-\mathrm{O}, \mathrm{OH}$, and $\mathrm{COOH}$ ) appeared on the biochar surface when organic solid wastes were modified by ferric chloride and pyrolyzed in an oxygen-free furnace. These functional groups with high specific surface areas, strong reducibility, and high concentration of radicals could result in $\mathrm{Cr}$ (III) coprecipitation or complexation with functional groups [35]. These results demonstrate that $\mathrm{CHBC}$ could notably reduce the leachability of $\mathrm{Cr}$ and $\mathrm{Cr}(\mathrm{VI})$ and can be applied in $\mathrm{Cr}(\mathrm{VI})$ contaminated soil remediation.

4.3. Bioaccessibility of $\mathrm{Cr}$ and $\mathrm{Cr}$ (VI) of Stabilized Soils. Figure 6 shows the bioaccessibility of $\mathrm{Cr}$ - and $\mathrm{Cr}(\mathrm{VI})$-stabilized soils with different $\mathrm{CHBC}$ dosages. The $\mathrm{Cr}(\mathrm{VI})$ and $\mathrm{Cr}$ concentrations in the SBET test decreased with the increase in $\mathrm{CHBC}$ dosage. When the $\mathrm{CHBC}$ dosage increased from $0 \%$ to $10 \%, \mathrm{Cr}(\mathrm{VI})$ and the total $\mathrm{Cr}$ decreased from 9.7 and $10.1 \mathrm{mg} / \mathrm{L}$ to 0.03 and $0.08 \mathrm{mg} / \mathrm{L}$, respectively. These findings suggest that the bioaccessibility risk of $\mathrm{Cr}$ decreased with the increasing CHBC dosage. The leachant used in the bioaccessibility test was a strong acid solution (with $\mathrm{pH}$ of 1.5); thus, the $\mathrm{Cr}$ in $\mathrm{CHBC}$-stabilized soils has high erosionresisting characteristics in a strong acid environment. This result agrees with the findings of Wang et al. [36] and Jobby et al. [37]. 


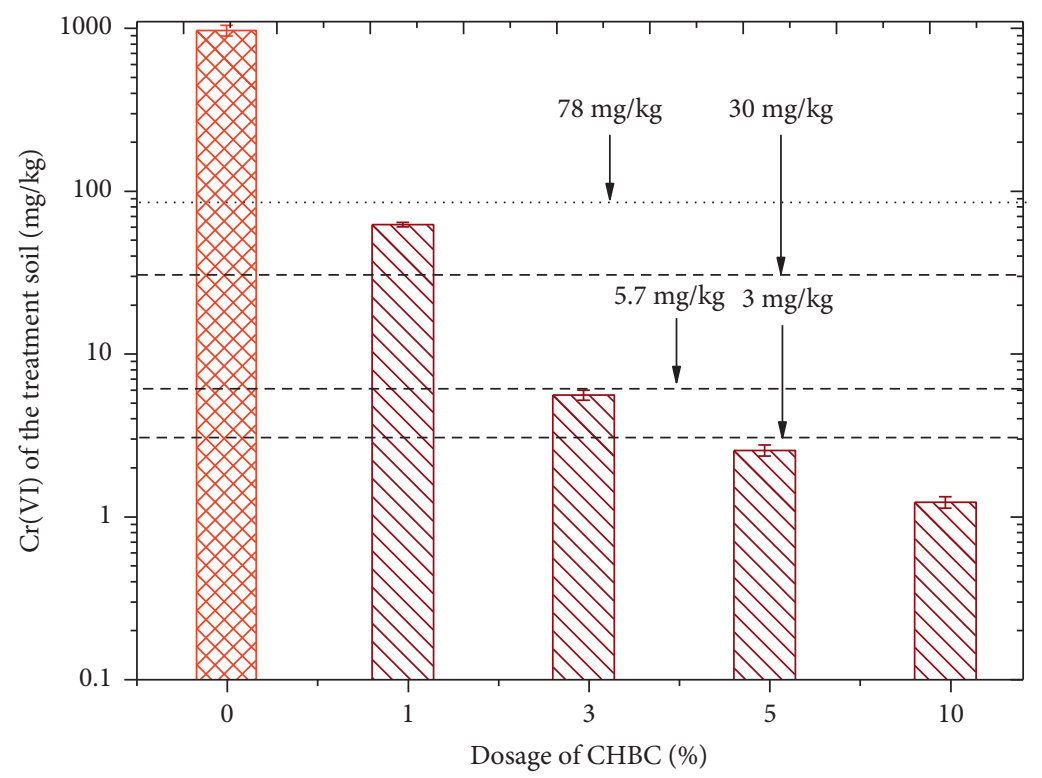

$X X X$ Contaminated soil $\triangle 1 \mathrm{CHBC}$

Figure 4: Effect of CHBC dosage on $\mathrm{Cr}(\mathrm{VI})$ content of stabilized soils.

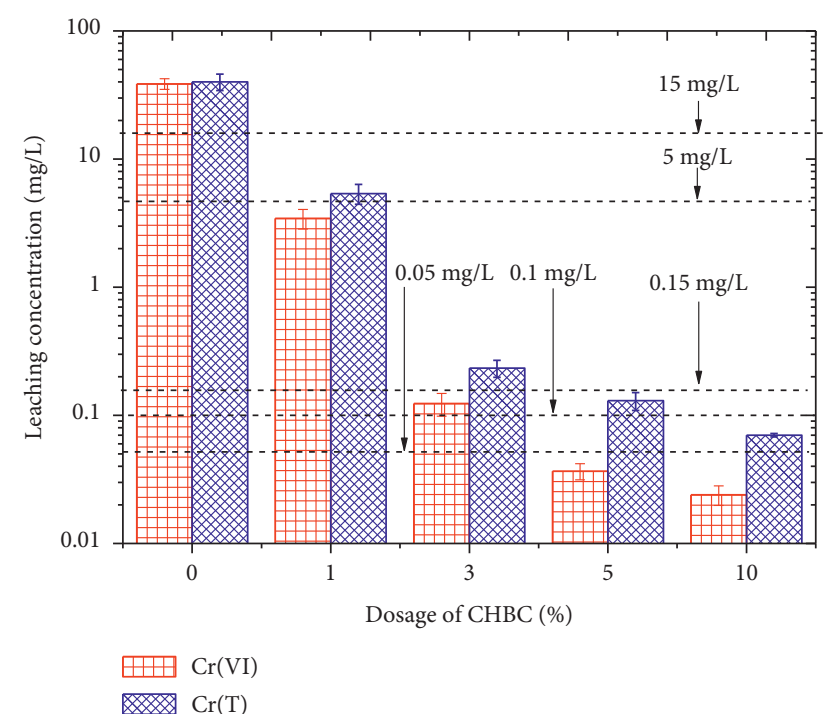

Figure 5: Effect of CHBC dosage on leachability of $\mathrm{Cr}$ and $\mathrm{Cr}(\mathrm{VI})$ of stabilized soils.

4.4. Speciation Distribution of $\mathrm{Cr}$ and $\mathrm{Cr}(\mathrm{VI})$ in Stabilized Soils. Figure 7 shows the speciation distribution of the $\mathrm{Cr}$ of stabilized soils with different $\mathrm{CHBC}$ dosages. Most of the $\mathrm{Cr}$ in the contaminated soil was in exchangeable fraction $(86.27 \%)$. However, the reducible $(7.73 \%)$, oxidizable (5.62\%), and residue fractions $(0.38 \%)$ were minimal. The $\mathrm{Cr}$ speciation in stabilized soils changed substantially, and the exchangeable fraction was converted to reducible, oxidizable, and residue fractions with $\mathrm{CHBC}$ addition. The exchangeable, reducible, oxidizable, and residue fractions decreased to $6.656 \%, 17.41 \%, 74.34 \%$, and $1.443 \%$, respectively, when the $\mathrm{CHBC}$ dosage was increased to $5 \%$. This phenomenon occurred because $\mathrm{Cr}(\mathrm{VI})$ was reduced to $\mathrm{Cr}$ (III) by $\mathrm{FeSO}_{4}$, and $\mathrm{Cr}$ (III) formed the $\mathrm{Cr}_{\mathrm{x}} \mathrm{Fe}_{1-\mathrm{x}}(\mathrm{OH})_{3}$ precipitate and complexation or complexed with functional groups [18, 35]. Figure 7 also displays the considerable decrease in reducible fraction from $17.41 \%$ to $5.47 \%$; the oxidizable and residue fractions increased from $74.34 \%$ to $89.53 \%$ and from $1.43 \%$ to $3.91 \%$, respectively, when the $\mathrm{CHBC}$ dosage was increased from $5 \%$ to $10 \%$. The decrease in reducible fraction can also be attributed to the active functional groups $(\mathrm{C}-\mathrm{H}, \mathrm{C}=\mathrm{O}, \mathrm{C}-\mathrm{O}$, and $\mathrm{OH})$. The $\mathrm{FeSO}_{4}$ levels increased with $\mathrm{CHBC}$ addition and caused the increased formation of Cr-organic complex and $\mathrm{Cr}_{\mathrm{x}} \mathrm{Fe}_{1-}$ ${ }_{x}(\mathrm{OH})_{3}$ precipitation. These results agree with the findings of Zhou et al. [12] and Agrafioti et al. [16]. Gabarrón et al. [38] and Zimmerman and Weindorf [39] observed that species distribution determines the leachability of heavy metals in stabilized soil. Zhang et al. [40] showed that the availability and mobility of heavy metals in soil are related to the content of exchangeable forms. These results demonstrate that CHBC substantially increases the chemical stability of $\mathrm{Cr}$ in stabilized soil. This alteration in the $\mathrm{Cr}$ speciation of $\mathrm{CHBC}$ stabilized soil accounts for the reduced leachability and bioaccessibility of $\mathrm{Cr}$.

4.5. Risk Assessment of $\mathrm{Cr}$ in Stabilized Soils. RAC, which considers the mobility fraction of metals, is used to identify the risk of heavy metals in contaminated soils. Figure 8 shows the effect of CHBC dosage on the RAC of stabilized soils. The RAC decreased with the increase in CHBC dosage. When the CHBC dosage increased from $0 \%$ to $10 \%$, the RAC decreased from 97.6 to 0.91 . This result suggests that the risk decreased from very-risky to no-risk condition. Figure 8 


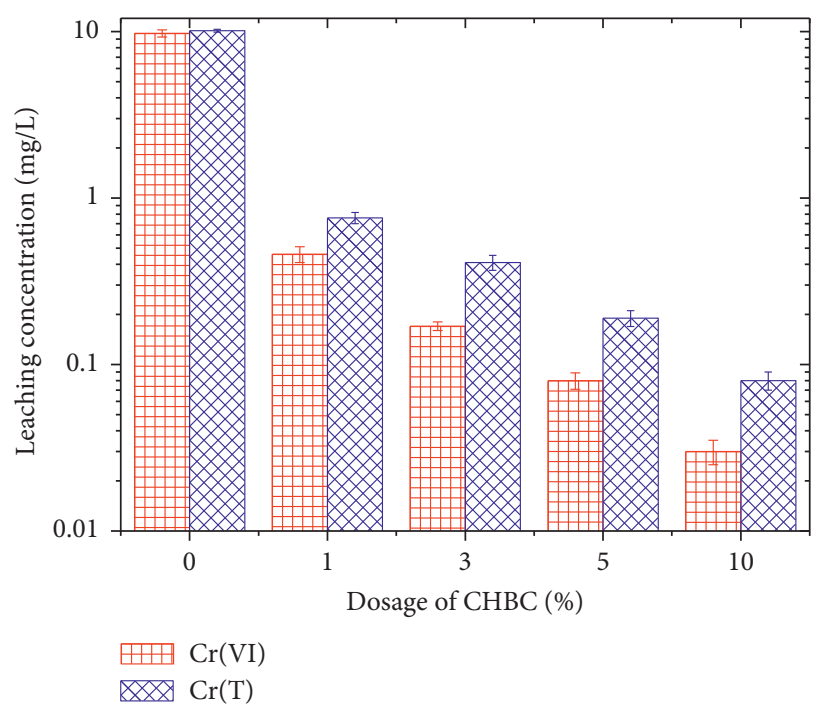

Figure 6: Effect of CHBC dosage on bioaccessibility of $\mathrm{Cr}$ and $\mathrm{Cr}(\mathrm{VI})$ of stabilized soils.

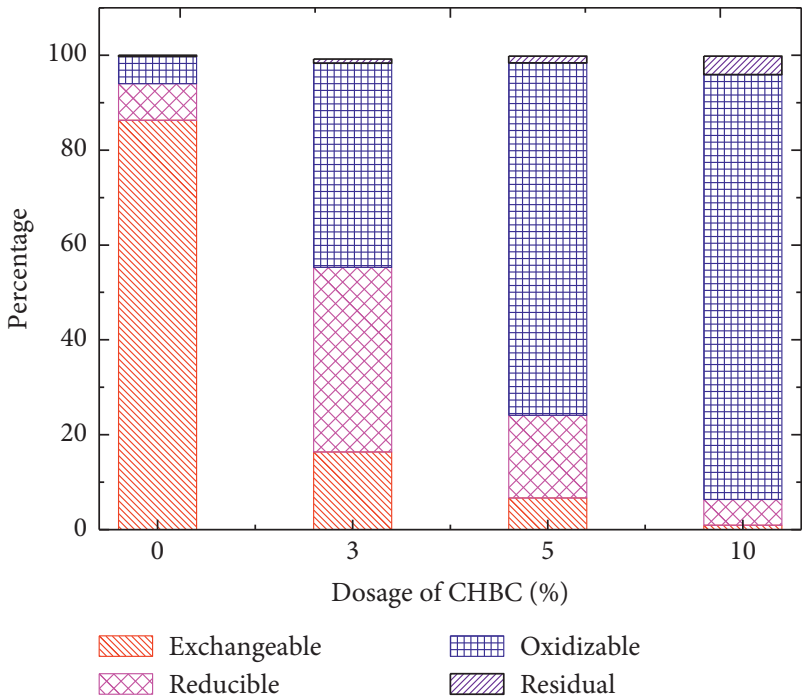

FIGURE 7: Effect of CHBC dosage on speciation distribution of $\mathrm{Cr}$ of stabilized soils.

shows that the RAC of the stabilized soils with $10 \%$ CHBC dosage indicates no risk. Giridharan et al. [41] and Sundaray et al. [42] noted that heavy metals in high-risk and veryhigh-risk categories are potentially bioavailable and may easily enter the food chain. Heavy metals in medium-risk categories of stabilized soil could be controlled by utilizing subgrade fill materials. Heavy metals in no-risk and low-risk categories are safe for the environment. The results of the risk assessment of stabilized soils agree with the $\mathrm{Cr}(\mathrm{VI})$ content findings on CHBC-stabilized soils. This phenomenon indicates that $\mathrm{CHBC}$ is a high-efficiency reducing agent in the remediation of $\mathrm{Cr}(\mathrm{VI})$-contaminated soils.

4.6. Probable Immobilization Mechanism of Cr. Figure 9 displays the $\mathrm{XRD}$ results of $\mathrm{Cr}(\mathrm{VI})$-contaminated and CHBC-stabilized soils. The contaminated soil showed the same distribution of peak position before and after stabilization with CHBC. Illite, quartz, albite, and montmorillonite were identified as the major phases in $\mathrm{Cr}(\mathrm{VI})$-contaminated and CHBC-stabilized soils. This result precludes the formation of new crystal lattices in CHBC-stabilized soil. The changes in the leachability, bioaccessibility, and speciation distribution of $\mathrm{Cr}$ in the contaminated soil before and after stabilization with $\mathrm{CHBC}$ can be attributed to the following reasons. (1) $\mathrm{Cr}(\mathrm{VI})$ was reduced to $\mathrm{Cr}(\mathrm{III})$ by active functional groups $\left(\mathrm{C}-\mathrm{H}, \mathrm{C}=\mathrm{O}, \mathrm{C}-\mathrm{O}\right.$, and $\mathrm{OH}$ ) and $\mathrm{FeSO}_{4}$. (2) $\mathrm{Cr}(\mathrm{III})$ formed $\left(\mathrm{Cr}_{\mathrm{x}} \mathrm{Fe}_{1-\mathrm{x}}(\mathrm{OH})_{3}\right.$ precipitates and complexed with carbonyl and carboxyl groups. The coupled redox reactions between $\mathrm{Cr}(\mathrm{VI})$ and $\mathrm{CHBC}$ are expressed in the following equations:

$$
\begin{gathered}
3 \mathrm{Fe}^{2+}+\mathrm{CrO}_{4}{ }^{2-}+8 \mathrm{H}_{2} \mathrm{O} \longrightarrow 4 \mathrm{Fe}_{0.75} \mathrm{Cr}_{0.25}(\mathrm{OH})_{3}+4 \mathrm{H}^{+} \\
\mathrm{HCrO}_{4}{ }^{-}+\mathrm{CHBC}+7 \mathrm{H}+\longrightarrow \mathrm{Cr}(\mathrm{III})+\text { partially oxidized }-\mathrm{CHBC}+\mathrm{CO}_{2}+4 \mathrm{H}_{2} \mathrm{O} \\
\mathrm{HCrO}_{4}{ }^{-}+7 \mathrm{H}^{+}+\text {reductive functional group } \longrightarrow \mathrm{Cr}(\mathrm{III})-\text { complexes }+\mathrm{CO}_{2}+4 \mathrm{H}_{2} \mathrm{O}
\end{gathered}
$$




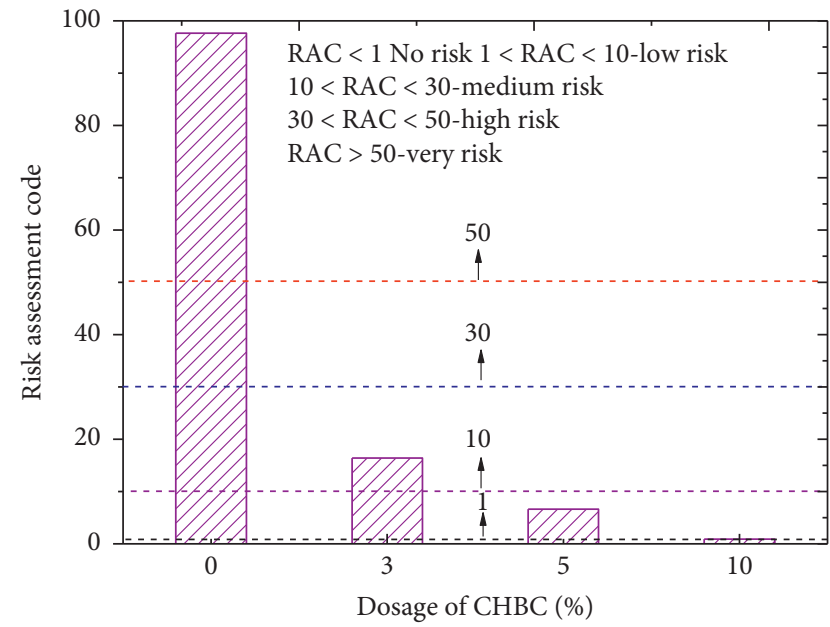

FIGURE 8: Effect of CHBC dosage on risk assessment of stabilized soils.

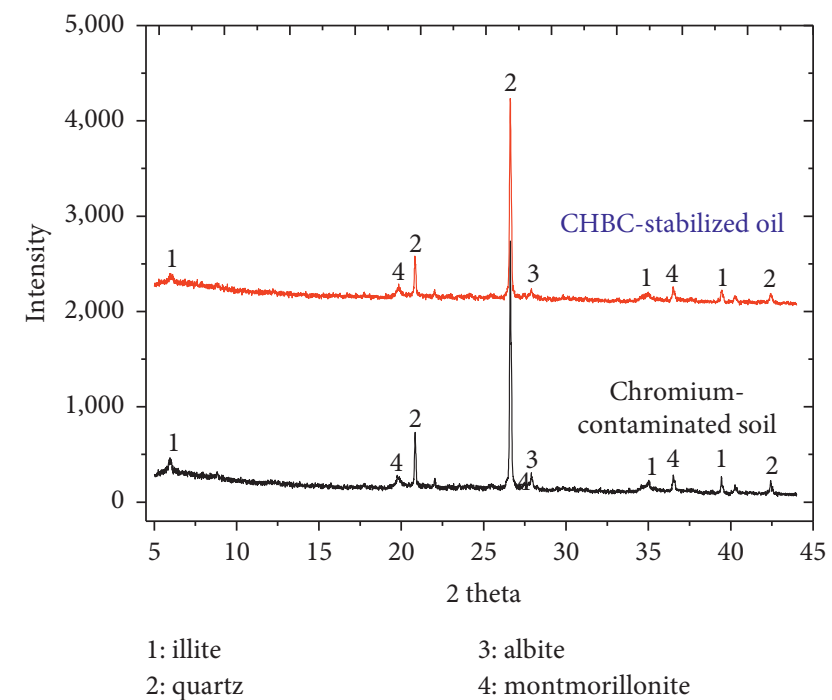

FIGURE 9: The XRD patterns of the Cr(VI)-contaminated soil and CHBC stabilized soil.

Kostarelos et al. [43] suggested that $\mathrm{Cr}(\mathrm{VI})$ is reduced to $\mathrm{Cr}(\mathrm{III})$ by $\mathrm{FeSO}_{4}$ and forms $\mathrm{Cr}(\mathrm{III})$ - $\mathrm{Fe}(\mathrm{III})$ hydroxide precipitates $\left(\mathrm{Cr}(\mathrm{OH})_{3}\right.$ and $\left.\mathrm{Cr}_{\mathrm{x}} \mathrm{Fe}_{1-\mathrm{x}}(\mathrm{OH})_{3}\right)$. Reyhanitabar et al. [44] and Tytłak et al. [45] observed that the sewage sludge biochar favors the $\mathrm{Cr}(\mathrm{VI})$ reduction into the less mobile $\mathrm{Cr}(\mathrm{III})$, which is the main mechanism for $\mathrm{Cr}(\mathrm{VI})$ stabilization in soil. Lu et al. [46] suggested that $\mathrm{Cr}$ (III) could form surface complexation with the free carboxyl and hydroxyl functional groups of CHBC. Chen et al. [47] reported that $\mathrm{Cr}(\mathrm{VI})$ and $\mathrm{Cr}(\mathrm{III})$ could form inner-sphere complexation and coprecipitation with the functional groups (-R-O-, -COO-, and -O-mineral oxides) of sewage sludge biochar. Costa et al. [35] noted that carboxyl (R-COOH) and alcoholic or phenolic hydroxyl groups (R-OH) are generally accepted as the main groups contributing to the coordination between $\mathrm{Cr}$ (III) and sorbent surfaces. Han et al. [48] suggested that the $\mathrm{Cr}(\mathrm{VI})$ removal mechanism of biochar is the electrostatic attraction on protonated $-\mathrm{OH}$ on the $\gamma-\mathrm{Fe}_{2} \mathrm{O}_{3}$ surface, and it could be stabilized in an acid solution. Miretzky et al. [49] and Tsang et al. [50] consider the $\mathrm{Cr}(\mathrm{VI})$ reduction by reductive functional groups (such as $\mathrm{C}=\mathrm{C}$ and $-\mathrm{COO}$ ) irreversible, whereas $\mathrm{Cr}(\mathrm{III})$ sorption is reversible in alkaline solutions. This result agrees with that of Oluwatuyi et al. [4, 51]. Thus, the leachability, bioaccessibility, and toxicity of $\mathrm{Cr}(\mathrm{VI})$ and $\mathrm{Cr}$ changed in the CHBC-stabilized soil.

\section{Conclusions}

This study developed $\mathrm{CHBC}$ as a new reductant for $\mathrm{Cr}(\mathrm{VI})$ contaminated soil. The effectiveness of CHBC-stabilized $\mathrm{Cr}(\mathrm{VI})$-contaminated soil was investigated by SPLP, SBET, alkaline digestion, sequential extraction, XRD, and RAC. The following conclusions were drawn:

(1) CHBC has high efficiency in stabilizing $\mathrm{Cr}(\mathrm{VI})$. This material can effectively reduce the leachability and bioavailability of $\mathrm{Cr}$ in contaminated soil. The $\mathrm{Cr}(\mathrm{VI})$ content in CHBC-stabilized soil at 3\% dosage is below the risk screening value of second-category development lands $(5.7 \mathrm{mg} / \mathrm{kg})$. The risk screening value of first-category development lands $(3.0 \mathrm{mg} / \mathrm{kg})$ was achieved with the CHBC dosage of $5 \%$. At CHBC dosages of $1 \%$ and $3 \%$, the $\mathrm{Cr}(\mathrm{VI})$ and $\mathrm{Cr}$ concentrations of stabilized soils meet the Standards for Hazardous Waste regulatory limit in China (5 and $15 \mathrm{mg} / \mathrm{L}$, respectively); the values for the Standard for Pollution Control on the Landfill Site of Municipal Solid Waste regulatory limit in China were also met (1.5 mg/L for $\mathrm{Cr}(\mathrm{VI})$ and $4.5 \mathrm{mg} / \mathrm{L}$ for $\mathrm{Cr}$ ). The $\mathrm{Cr}(\mathrm{VI})$ and $\mathrm{Cr}$ concentrations of the stabilized soils were lower than the China Environmental Quality Standards of surface water for the agriculture and civil use regulatory limit $(0.1$ and $0.05 \mathrm{mg} / \mathrm{L}$, respectively) when the CHBC dosages were $5 \%$ and $10 \%$.

(2) CHBC substantially reduced the environmental risk of $\mathrm{Cr}$ in the stabilized soil. The risk of $\mathrm{Cr}$ in the stabilized soil decreased from very risky to no risk, and the exchangeable fraction of $\mathrm{Cr}$ was mainly converted to oxidizable fraction when the CHBC dosage was increased from $0 \%$ to $10 \%$. The changes in leachability, bioaccessibility, and risk of $\mathrm{Cr}(\mathrm{VI})$ and $\mathrm{Cr}$ in stabilized soil were attributed to the reaction between $\mathrm{CHBC}$ and $\mathrm{Cr}(\mathrm{VI})$ and $\mathrm{Cr}$. $\mathrm{Cr}(\mathrm{VI})$ was reduced to $\mathrm{Cr}$ (III) by $\mathrm{FeSO}_{4}$, whereas $\mathrm{Cr}$ (III) formed the $\mathrm{Cr}_{\mathrm{x}} \mathrm{Fe}_{1-\mathrm{x}}(\mathrm{OH})_{3}$ precipitate and complexations or complexed with the functional groups of CHBC.

\section{Data Availability}

The data used to support the findings of this study are included within the article.

\section{Disclosure}

Yuan-Yuan Li and Ting-Ting Zhang are regarded as the cofirst authors. 


\section{Conflicts of Interest}

The authors declare no conflicts of interest.

\section{Authors' Contributions}

Yuan-Yuan Li and Ting-Ting Zhang contributed to the work equally.

\section{Acknowledgments}

This study was supported by the National Key Research and Development Project (2019YFC1803605 and 2019YFC1803903), the University Research Project of Shandong Province (J18KB059), and the Natural Science Foundation of Qingdao University of Technology, Linyi (2017ZR002, 2017ZR004, and 2018TJZR002).

\section{References}

[1] O. E. Oluwatuyi, O. O. Ojuri, and A. Khoshghalb, "Cementlime stabilization of crude oil contaminated kaolin clay," Journal of Rock Mechanics and Geotechnical Engineering, vol. 12, no. 1, pp. 160-167, 2020.

[2] Y. Li, X. Xu, and J. Liu, "The hazard of chromium exposure to neonates in Guiyu of China," Science of the Total Environment, vol. 403, no. 1-3, pp. 99-104, 2008.

[3] Y. Gao and J. Xia, "Chromium contamination accident in China: viewing environment policy of china," Environmental Science \& Technology, vol. 45, no. 20, pp. 8605-8606, 2011.

[4] O. E. Oluwatuyi, E. C. Ashaka, and O. O. Ojuri, "Cement stabilization treatment of lead and naphthalene contaminated lateritic soils," Journal of Environmental Engineering and Landscape Management, vol. 27, no. 1, pp. 41-48, 2019.

[5] D. Dermatas, M. Chrysochoou, D. H. Moon, D. G. Grubb, M. Wazne, and C. Christodoulatos, "Ettringite-induced heave in chromite ore processing residue (COPR) upon ferrous sulfate treatment," Environmental Science \& Technology, vol. 40, no. 18, pp. 5786-5792, 2006.

[6] D. Li, C. Gui, and G. Ji, "An interpretation to Cr (VI) leaching concentration rebound phenomenon with time in ferrousreduced $\mathrm{Cr}(\mathrm{VI})$-bearing solid matrices," Journal of Hazardous Materials, vol. 378, 2019.

[7] M. Chrysochoou, D. R. Ferreira, and C. P. Johnston, "Calcium polysulfide treatment of Cr (VI) contaminated soil," Journal of Hazardous Materials, vol. 179, no. 1-3, pp. 650-657, 2010.

[8] X. Dong, L. Q. Ma, and Y. Li, "Characteristics and mechanisms of hexavalent chromium removal by biochar from sugar beet tailing," Journal of Hazardous Materials, vol. 190, no. 1-3, pp. 909-915, 2011.

[9] E. Agrafioti, D. Kalderis, and E. Diamadopoulos, "Arsenic and chromium removal from water using biochars derived from rice husk, organic solid wastes and sewage sludge," Journal of Environmental Management, vol. 133, pp. 309-314, 2014.

[10] Y. Ma, W.-J. Liu, N. Zhang, Y.-S. Li, H. Jiang, and G.-P. Sheng, "Polyethylenimine modified biochar adsorbent for hexavalent chromium removal from the aqueous solution," Bioresource Technology, vol. 169, pp. 403-408, 2014.

[11] Y.-S. Shen, S.-L. Wang, Y.-M. Tzou, Y.-Y. Yan, and W.-H. Kuan, "Removal of hexavalent $\mathrm{Cr}$ by coconut coir and derived chars - the effect of surface functionality," Bioresource Technology, vol. 104, pp. 165-172, 2012.
[12] Y. Zhou, B. Gao, A. R. Zimmerman, H. Chen, M. Zhang, and X. Cao, "Biochar-supported zerovalent iron for removal of various contaminants from aqueous solutions," Bioresource Technology, vol. 152, pp. 538-542, 2014.

[13] S. Xia, Z. Song, P. Jeyakumar et al., "Characteristics and applications of biochar for remediating $\mathrm{Cr}(\mathrm{VI})$-contaminated soils and wastewater[J]," Environmental Geochemistry and Health, vol. 42, no. 6, pp. 1543-1567, 2019.

[14] B. Li, J. Yang, W. Sun et al., "Carbonization of plant residues decreased their capability of reducing hexavalent chromium in soils," Water, Air, \& Soil Pollution, vol. 230, p. 300, 2019.

[15] G. Pei, Y. Zhu, J. Wen, Y. Pei, and H. Li, "Vinegar residue supported nanoscale zero-valent iron: remediation of hexavalent chromium in soil," Environmental Pollution, vol. 256, Article ID 113407, 2020.

[16] E. Agrafioti, D. Kalderis, and E. Diamadopoulos, "Ca and Fe modified biochars as adsorbents of arsenic and chromium in aqueous solutions," Journal of Environmental Management, vol. 146, pp. 444-450, 2014.

[17] W. Zhang, S. Mao, H. Chen, L. Huang, and R. Qiu, "Pb(II) and $\mathrm{Cr}(\mathrm{VI})$ sorption by biochars pyrolyzed from the municipal wastewater sludge under different heating conditions," Bioresource Technology, vol. 147, pp. 545-552, 2013.

[18] G. Chen, X. Wang, J. Li et al., "Environmental, energy, and economic analysis of integrated treatment of municipal solid waste and sewage sludge: a case study in China," Science of the Total Environment, vol. 647, pp. 1433-1443, 2019.

[19] J. Chen, X.-z. Meng, A. Bergman, and R. U. Halden, "Nationwide reconnaissance of five parabens, triclosan, triclocarban and its transformation products in sewage sludge from China," Journal of Hazardous Materials, vol. 365, pp. 502-510, 2019.

[20] L.-Y. Gao, J.-H. Deng, G.-F. Huang et al., "Relative distribution of $\mathrm{Cd}^{2+}$ adsorption mechanisms on biochars derived from rice straw and sewage sludge," Bioresource Technology, vol. 272, pp. 114-122, 2019.

[21] H. Su, Z. Fang, P. E. Tsang et al., "Remediation of hexavalent chromium contaminated soil by biochar-supported zerovalent iron nanoparticles," Journal of Hazardous Materials, vol. 318, pp. 533-540, 2016.

[22] US EPA, Acid Digestion of Sediments, Sludges and Soils, EPA 3050 B, US Geological Survey, Washington, DC, USA, 1996.

[23] USEPA, Synthetic Precipitation Leaching Procedure, EPA 1312, US Geological Survey, Washington, DC, USA, 1998.

[24] USEPA, Alkaline Digestion for Hexavalent Chromium, EPA 3060A, US Environmental Protection Agency, Washington, DC, USA, 1996.

[25] USEPA, Chromium Hexavalent Colorimetric, EPA 7196A, US Environmental Protection Agency, Washington, DC, USA, 1992.

[26] USEPA, Estimation of Relative Bioavailability of Lead in Soil and Soil-like Materials Using in Vivo and in Vitro Methods, EPA 9285-R-7-77, Office of Solid Waste and Emergency Response, Washington, DC, USA, 2007.

[27] A. G. Oomen, A. Hack, M. Minekus et al., "Comparison of five in vitro digestion models to study the bioaccessibility of soil contaminants," Environmental Science \& Technology, vol. 36, no. 15 , pp. 3326-3334, 2002.

[28] G. Rauret, J. F. López-Sánchez, A. Sahuquillo et al., "Improvement of the BCR three step sequential extraction procedure prior to the certification of new sediment and soil reference materials," Journal of Environmental Monitoring, vol. 1, no. 1, pp. 57-61, 1999. 
[29] G. Perin, L. Craboledda, and M. Lucchese, "Heavy metal speciation in the sediments of northern Adriatic Sea: a new approach for environmental toxicity determination," Heavy Metals in the Environment, vol. 2, no. 1, pp. 454-456, 1985.

[30] GB, Soil Environment Quality Risk Control Standard for Soil Contamination of Development Land, 36600, Ministry of Environmental Protection of the People's Republic of China, Beijing, China, 2018.

[31] T.-T. Zhang, Q. Xue, and M.-L. Wei, "Leachability and stability of hexavalent-chromium-contaminated soil stabilized by ferrous sulfate and calcium polysulfide," Applied Sciences, vol. 8, no. 9, p. 1431, 2018.

[32] GB/T, Identification Standards for Hazardous Wastes-Identification for Extraction Toxicity, Vol. 5085.3, Ministry of Environmental Protection of the People's Republic of China, Beijing, China, 2007.

[33] GB, Standard for Pollution Control on the Landfill Site of Municipal Solid Waste, Ministry of Environmental Protection of the People's Republic of China, Beijing, China, 16889.

[34] GB, Environmental Quality Standards for Surface Water, 3838, Ministry of Environmental Protection of the People's Republic of China, Beijing, China, 2002.

[35] J. F. d. S. S. Costa, V. J. P. Vilar, C. M. S. Botelho, E. A. B. da Silva, and R. A. R. Boaventura, "Application of the NernstPlanck approach to lead ion exchange in Ca-loaded Pelvetia canaliculata," Water Research, vol. 44, no. 13, pp. 3946-3958, 2010.

[36] L. Wang, N. Wang, L. Zhu, H. Yu, and H. Tang, "Photocatalytic reduction of $\mathrm{Cr}(\mathrm{VI})$ over different $\mathrm{TiO} 2$ photocatalysts and the effects of dissolved organic species," Journal of Hazardous Materials, vol. 152, no. 1, pp. 93-99, 2008.

[37] R. Jobby, P. Jha, A. K. Yadav, and N. Desai, "Biosorption and biotransformation of hexavalent chromium [Cr(VI)]: a comprehensive review," Chemosphere, vol. 207, pp. 255-266, 2018.

[38] M. Gabarrón, R. Zornoza, S. Martínez-Martínez, V. A. Muñoz, Á. Faz, and J. A. Acosta, "Effect of land use and soil properties in the feasibility of two sequential extraction procedures for metals fractionation," Chemosphere, vol. 218, pp. 266-272, 2019.

[39] A. J. Zimmerman and D. C. Weindorf, "Heavy metal and trace metal analysis in soil by sequential extraction: a review of procedures," International Journal of Analytical Chemistry, vol. 2010, Article ID 387803, 7 pages, 2010.

[40] T. T. Zhang, Q. Xue, J. S. Li et al., "Effect of ferrous sulfate dosage and soil particle size on leachability and species distribution of chromium in hexavalent chromium-contaminated soil stabilized by ferrous sulfate," Environmental Progress \& Sustainable Energy, vol. 38, no. 2, pp. 500-507, 2019.

[41] L. Giridharan, T. Venugopal, and M. Jayaprakash, "Speciation technique for the risk assessment of trace metals in the bed sediments of River Cooum, South India," Chemical Speciation \& Bioavailability, vol. 22, no. 2, pp. 71-80, 2010.

[42] S. K. Sundaray, B. B. Nayak, and S. Lin, "Geochemical speciation and risk assessment of heavy metals in the river estuarine sediments-a case study: mahanadi basin, India," Journal of Hazardous Materials, vol. 186, no. 2-3, pp. 18371846, 2011.

[43] K. Kostarelos, E. Rao, and D. Reale, "Reduction of Cr (VI) to Cr (III) in artificial, contaminated soil using ferrous sulfate heptahydrate and sodium thiosulfate," Practice Periodical of Hazardous, Toxic, and Radioactive Waste Management, vol. 13, no. 2, pp. 1823-1828, 2009.
[44] A. Reyhanitabar, L. Alidokht, and S. Oustan, "Application of stabilized Fe0nanoparticles for remediation of $\mathrm{Cr}(\mathrm{VI})$-spiked soil," European Journal of Soil Science, vol. 63, no. 5, pp. 724-732, 2012.

[45] A. Tytłak, P. Oleszczuk, and R. Dobrowolski, "Sorption and desorption of $\mathrm{Cr}(\mathrm{VI})$ ions from water by biochars in different environmental conditions," Environmental Science and Pollution Research International, vol. 22, no. 8, pp. 5985-5994, 2015.

[46] H. Lu, W. Zhang, Y. Yang, X. Huang, S. Wang, and R. Qiu, "Relative distribution of $\mathrm{Pb}^{2+}$ sorption mechanisms by sludgederived biochar," Water Research, vol. 46, no. 3, pp. 854-862, 2012.

[47] B. Chen and Z. Chen, "Sorption of naphthalene and 1naphthol by biochars of orange peels with different pyrolytic temperatures," Chemosphere, vol. 76, no. 1, pp. 127-133, 2009.

[48] Y. Han, X. Cao, X. Ouyang, S. P. Sohi, and J. Chen, “Adsorption kinetics of magnetic biochar derived from peanut hull on removal of $\mathrm{Cr}(\mathrm{VI})$ from aqueous solution: effects of production conditions and particle size," Chemosphere, vol. 145, pp. 336-341, 2016.

[49] P. Miretzky and A. F. Cirelli, "Cr (VI) and Cr (III) removal from aqueous solution by raw and modified lignocellulosic materials: a review," Journal of Hazardous Materials, vol. 180, no. 1-3, pp. 1-19, 2010.

[50] D. C. W. Tsang, F. Zhou, and W. Zhang, "Stabilization of cationic and anionic metal species in contaminated soils using sludge-derived biochar," Chemosphere, vol. 149, pp. 263-271, 2016.

[51] O. E. Oluwatuyi and O. O. Ojuri, "Environmental performance of lime-rice husk ash stabilized lateritic soil contaminated with lead or naphthalene," Geotechnical and Geological Engineering, vol. 35, no. 6, pp. 2947-2964, 2017. 